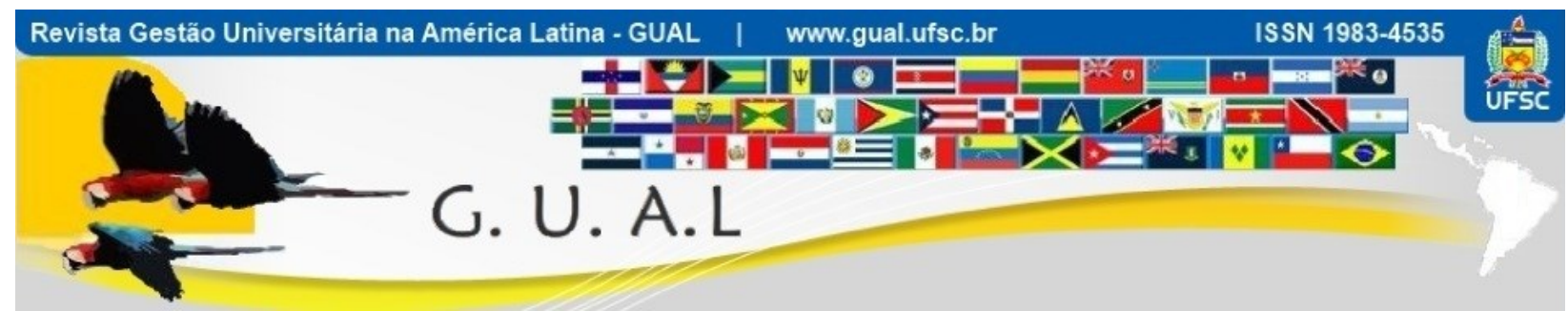

DOI: http://dx.doi.org/10.5007/1983-4535.2015v8n3p48

\title{
ORIENTAÇÃO ESTRATÉGICA: ANÁLISE DO COMPORTAMENTO DE COORDENADORES DE CURSO DE UMA UNIVERSIDADE PÚBLICA FEDERAL
}

\section{STRATEGIC ORIENTATION: ANALYSIS OF COURSE OF COORDINATORS OF BEHAVIOUR OF A FEDERAL PUBLIC UNIVERSITY}

Deosir Flávio Lobo de Castro Junior, Doutor Instituto Federal de Santa Catarina - IFSC deosir@ifsc.edu.br

Elvis Silveira-Martins, Doutor Universidade Federal de Pelotas - UFPel elvis.professor@gmail.com

Márcio Nakayama Miura, Doutor Universidade Estadual do Oeste do Paraná - UNOESTE adm.miura@gmail.com

Marcelo Augosto Menezes Deluca, Doutorando Universidade Federal de Santa Catarina - UFSC mdeluca@linhalivre.net

Alexandre Marino Costa, Doutor Universidade Federal de Santa Catarina - UFSC marinocad@gmail.com

Recebido em 14/abril/2014

Aprovado em 14/julho/2015

Sistema de Avaliação: Double Blind Review

Esta obra está sob uma Licença Creative Commons Atribuição-Uso. 


\title{
RESUMO
}

Diferentes tipologias de posicionamento gerencial têm sido elaboradas por pesquisadores cujas linhas de pesquisa circundam a estratégia. Parece haver consenso entre estes pesquisadores que uma das tipologias com crivo científico é a desenvolvida por Miles e Snow (1978). Sob outro aspecto, as organizações educacionais têm vivenciado diferentes (re) configurações procurando se adaptar às recentes necessidades da sociedade e ao público acadêmico que hoje é multifacetado em termos de origens, perspectivas e expectativas. Desta maneira objetiva-se com esta pesquisa identificar o comportamento estratégico predominante dos coordenadores de uma Universidade Pública Federal. Para o desenvolvimento da pesquisa foi realizada uma pesquisa de caráter quantitativo, com o uso da técnica survey. A amostra compreendeu 46 coordenadores, e estes dados foram tratados valendo-se de técnicas multivariadas. Os resultados acusaram que o comportamento predominante dos coordenadores de curso é o defensor. Na sequência foram identificados os comportamentos reativo, prospector e analista, nesta ordem. Concluiu-se que a orientação estratégica da maioria dos coordenadores de curso segue uma linha conservadora, realizando apenas as práticas que foram planejadas quando do desenvolvimento do projeto pedagógico dos cursos, desconsiderando a proposição de inovações. Chamou a atenção o fato de em segundo lugar ser identificado o comportamento reativo.

Palavras-Chave: Comportamento estratégico. Ensino Superior. Gestão universitária.

\begin{abstract}
Different managerial position typologies have been developed by researchers whose research lines surrounding the strategy. There seems to be consensus among the researchers, one of the types that with scientific riddle is developed by Miles and Snow (1978). In another aspect, the last educational organizations have experienced different settings trying to adapt the latest needs of society and the academic public that today is multifaceted in terms of backgrounds, perspectives and expectations. This objective way up with this research identify the predominant strategic behavior of the coordinators of a Federal Public University. For the development of a quantitative research study was carried out using the survey technique. The sample included 46 coordinators, and these data were treated making use of multivariate techniques. Results indicated that the predominant behavior of the course coordinators is the defender. Following on the reactive behaviors were identified, prospectus and analyst, in that order. It is concluded that the strategic direction of most course coordinators follows a conservative line, only performing the practices that were planned when the development of the education program of courses, disregarding the proposals for innovations. Of note was the fact secondly be identified reactive behavior.
\end{abstract}

Keywords: Strategic behavior. University. University management. 


\section{INTRODUÇÃO}

A Central Intelligence Agency (2015), destaca que a participação do setor de serviços no Brasil é responsável por $68,1 \%$ do Produto Interno Bruto (PIB). Pelos dados do Instituto Brasileiro de Geografia e Estatística - IBGE (2015) é possível verificar que em 2011, segundo a Pesquisa Anual de Serviços (PAS), foi estimada a existência de 1.081 .012 empresas no setor, responsáveis pela receita operacional líquida de $\mathrm{R} \$ 1,004$ trilhões e gerando mais de 11,3 milhões de empregos e dois segmentos se destacaram: serviços profissionais, administrativos e complementares e os serviços prestados principalmente às famílias, incluindo a educação continuada.

Ao se verificar o crescimento de Instituições de Ensino Superior (IES), pelos dados do censo educacional do ensino superior, e ao se analisar a série dos anos de 1991 até 2012, os números de IES passou de 893 para 2.416. Em 1991, havia 4.908 cursos superiores ofertados no Brasil; já em 2012, esse número cresce para 31.886. No sul do país são 409 IES e cerca de 5.930 cursos, não contando os cursos oferecidos na modalidade à distância (INEP, 2014).

Onusic (2011) afirma que o setor de educação superior é considerado um serviço de aperfeiçoamento de relevância na sociedade. Assim sendo, uma Instituição de Ensino Superior, seja ela pública ou privada, constitui uma organização que presta serviços a seus clientes e desta forma afeta a sociedade. A autora explica que com o crescimento do número de instituições privadas na educação, é perceptível a preocupação da gestão destas IES, que se evidencia pelo ambiente competitivo em que está inserida a educação atualmente. Estudos organizacionais há tempos buscam por tipologias e taxonomias genéricas que auxiliem os gestores nas tomadas de decisões e melhoria de desempenho.

$\mathrm{Na}$ década de 70 , tanto pesquisadores quanto gestores das organizações procuraram por taxonomias de estratégias genéricas, cujas escolhas estratégicas e aplicação fossem generalizadas nas indústrias ou tipos de organizações, objetivando facilitar a gestão das organizações e melhorar seu desempenho. Carneiro, Cavalcanti e Deschamps-Silva (1997) apresentam as principais taxonomias de estratégias genéricas, citando os trabalhos de Miles e Snow (1978); Porter (1980); Hambrick (1983) e Mintzberg (1988). Dentre as alternativas, a aceitação dos estudos configuracionais de Miles e Snow (1978) não abordam somente as alternativas estratégicas, mas também o empreendedorismo, a estrutura e os processos da organização. 
As empresas podem ser classificadas facilmente em uma de quatro categorias teóricas, e seus comportamentos podem ser previstos com base na sua classificação como defensivos, prospectores, analíticos ou reativos (GIMENEZ et al., 1999; SLATER; OLSON, 2000; RIBEIRO; ROSSETTO; VERDINELLI, 2011).

Silveira-Martins (2012) verificou as relações realizadas entre o comportamento estratégico e as seguintes variáveis: desempenho organizacional; características do executivo; padrões de estratégia; vantagem competitiva e competitividade; planejamento estratégico; grupos estratégicos; estratégia das filiais e a formação de capacidade. Essas variáveis foram estudados pelos seguintes autores: Hambrick (1983), Dess e Davis (1984), White (1986), Covin (1991), Thomas, Litschert e Ramaswany (1991), Beal e Yasai-Ardekani (2000), Slater, Olson e Hult (2006), e Silveira-Martins (2012).

Miles e Snow (1978) desenvolveram uma tipologia genérica para a solução dos problemas de engenharia, empreendedor e estrutural. Sua tipologia é adequada à existência de um mercado caracterizado por grande número de organizações competindo entre si. Escalas e medidas foram estudadas e desenvolvidas por Zahra e Pearce II (1990), Conant, Mokwa e Varadarajan (1990), Hambrick (2003), e Verdinelli e Escobar (2011).

Diante do exposto, objetiva-se com esta pesquisa identificar o comportamento estratégico predominante dos coordenadores de uma Universidade Pública Federal.

\section{FUNDAMENTAÇÃO TEÓRICA}

Um tema é considerado relevante quando está ligado a questões importantes para um ou mais segmentos da sociedade, podendo também estar ligado a uma questão teórica que mereça atenção na literatura especializada (MATTAR, 1999).

Akkari (2001) observa pelo ponto de vista organizacional e quantitativo, verifica que o sistema educativo brasileiro progrediu muito nessas últimas décadas. Neste período houve um aumento sensível das taxas de escolarização em todos os níveis de ensino e uma baixa das taxas de analfabetismo.

De fato, na classificação internacional da precariedade dos sistemas educativos nos países em desenvolvimento, o Brasil está 16 lugares abaixo de sua posição em relação ao PIB. Tureta, Rosa, Oliveira, (2007) afirmam quem em todo o mundo, existe uma forte influência sobre o setor educacional. No ensino superior, as mudanças se caracterizam pelas necessárias 
adaptações de seus enfoques e contextualização, sendo o fator econômico recebendo um importante destaque.

Willborn (1986), Collier (1987) e Rhyne (1988) concluíram que a garantia da qualidade de uma empresa de serviço é tarefa de seus gestores. Ao estudar os serviços, o atendimento e os níveis de qualidade dos serviços, verificou-se que a oferta de serviços aos clientes consiste o desafio da qualidade, uma vez que os clientes estão mais exigentes. Este desafio deve ser compromisso a longo prazo da direção de qualquer organização.

Assim sendo, o sistema de entrega de serviço, obrigatoriamente passa pela gestão, sendo recomendável levar em consideração desde o planejamento até a operação.

\subsection{COMPORTAMENTOS ESTRATÉGICOS}

Pela diversidade dos modelos propostos para o estudo do comportamento estratégico das organizações, não parece existir uma univocidade em torno de uma terminologia, visto que alguns trabalhos referem-se a tipologias ou tipos estratégicos, postura estratégica, orientação estratégica ou mesmo comportamento estratégico. Em consonância com a pesquisa de Carvalho (2011), serão todas as terminologias tratadas e entendidas como sinônimos para comportamento estratégico.

Mintzberg (1973) demonstra que a preocupação e a busca pela compreensão da elaboração de estratégias organizacionais vem de algum tempo quando, apresenta a inquietação por meio de seu questionamento de como as organizações tomam as decisões importantes e como as vinculam à formulação de estratégias.

Em sua pesquisa, Mintzberg (1973), informa a existência de três modos para se realizar uma estratégia organizacional:

i) Modo Empreendedor,

ii) Modo Adaptativo, e

iii) Modo de Planejamento.

O modo empreendedor possui como características: a busca por novas oportunidades, sendo que as resoluções dos problemas está em um plano secundário. O gestor se desenvolve em condições de maior incerteza, com ações audazes.

O modo adaptativo é caracterizado por ação dos gestores que procedem de soluções reativas a problemas existentes, não agindo de maneira pró-ativa. 
O modo de planejamento inicia com a coleta sistemática de informações apropriadas para a análise da situação, desta forma se percebe sua formalidade na realização de metas precisas. A execução de alternativas estratégicas e a seleção são sempre de maneira racional.

De acordo com Mintzberg (1973), apresenta uma desmistificação do processo de planejamento, afirmando não ser uma panaceia para os problemas da estratégia de tomada de decisões. Em vez disso, esclarece que na verdade encontra-se um foco em modelos abstratos, processos simples de planejamento para elaborar as estratégias e tomada de decisões.

Um ambiente imprevisível como o mercado competitivo sugere o uso do modo adaptativo, assim como a presença de um líder poderoso pode permitir que a organização atinja de maneira mais satisfatória seus objetivos por meio do modo empresarial.

Para Robinson Jr. e Pearce II (1988), a orientação estratégica, enfatizando a inovação de produtos ou aqueles que incorporaram eficiência e diferenciação em seus padrões de comportamento estratégico, é associada a níveis de desempenho significativamente mais elevados.

Segev (1989) por sua vez, em seu estudo sistematizado e avaliativo, encontrou 31 variáveis estratégicas. Neste estudo foi comparado as tipologias mais frequentes em estudos de estratégias competitivas genéricas: a tipologia de Miles e Snow (1978) com os possíveis comportamentos estratégicos e a adaptação organizacional: i) Prospector, ii) Defensor, iii) Analista, e iv) Reativo; e a outra tipologia apresentada sendo a de Porter (1980): i) Liderança de custo total; ii) Diferenciação, Foco; e Stuck in the Middle - quando a organização não consegue se posicionar e fica presa entre duas estratégias.

Com esta pesquisa, foi verificada que a tipologia de Porter se encontra principalmente em setores mais concentrados, com unidades de negócios maiores, enquanto a tipologia de Miles e Snow é adequada em indústrias com mais concorrentes. Com a competição acirrada no fenômeno denominado de globalização, a tipologia de Miles e Snow (1978) é considerada mais adequada aos mercados com maior número de competidores e diferentes estratégias (SEGEV, 1989).

Covin (1991) corrobora as expectativas sobre os atributos estratégicos e sobre a correlação com o desempenho, dadas as diferentes posturas estratégicas. Sugere que os comportamentos estratégicos das empresas conservadoras podem diferir bastante daqueles das empresas empreendedoras. O comportamento estratégico parece exercer uma grande influência sobre as práticas de negócios individuais e sobre as táticas competitivas que 
coletivamente compreendem uma firme estratégia. Dessa forma, a personalidade do tomador de decisão deverá influenciar a estratégia escolhida pela organização, sendo um reflexo de tal personalidade.

Ferreira e Ramos (2004) informam que diversos estudos enfocaram as peculiaridades do empreendedor. O foco está na maneira como são coletadas, processadas e analisadas as informações, ou seja, o estilo cognitivo. A relação está entre a forma de processar a informação e o processo de escolhas estratégicas da organização. A tomada de decisão estratégica consiste no estilo, que determina a escolha, conduzindo à estratégia correta.

Brunaldi, Jungles e Gimenez (2007) informam que estrutura organizacional e comportamento organizacional são componentes essenciais para a implementação de estratégias, sendo lógico que um desempenho superior aos concorrentes estará subordinado à forma com que esses elementos se alinham aos requisitos da estratégia específica.

Gardelin, Rossetto, e Verdinelli (2011) apresentam os desafios incessantes que as organizações enfrentam no seu cotidiano, advindos de uma diversidade de fatores que são determinados pelo ambiente. São considerados desde os fatores mais simples até os mais complexos. As alterações na configuração do ambiente afetam de alguma forma o comportamento dos gestores e, por consequência, o comportamento organizacional no seu ambiente. As transformações econômicas (como a crise financeira internacional de 2008), tecnológicas, sociais e políticas fazem com que as organizações se adaptem, ou então estarão fadadas ao fracasso. A isso se deve o destaque do comportamento estratégico.

Zahra e Pearce II (1990) informam que a tipologia de Miles e Snow foi a tipologia mais popular nas pesquisas de estratégias de negócio nos anos 80. Eles citam diversos estudos e as indústrias testadas. Autores como Snow e Hrebiniak (1980) no setor automotivo, transporte aéreo e plásticos semicondutores; Hambrick $(1980,1981)$ em hospitais e no ensino superior.

Zajac e Shortell (1989) estudaram e testaram a taxonomia em uma diversidade de organizações, tais como: faculdades, hospitais, seguradoras, bancos, empresas automotivas, companhias aéreas, indústria de plástico dentre outras. No setor da educação foram encontrados dois comportamentos estratégicos, com 59\% o comportamento prospector e com $41 \%$ defensivo. 


\subsection{MILES E SNOW (1978)}

A tipologia de Miles e Snow (1978) inicia-se com o objetivo de desenvolver uma compreensão do processo pelo qual a organização continuamente ajuste-se ao seu ambiente. Organizações eficazes esculpem e mantêm um mercado viável para os seus produtos ou serviços. Para isso, devem se adaptar ao ambiente.

Os autores apresentam três problemas a que o gestor deve se adaptar, sendo eles:

i) O problema empreendedor, em primeiro lugar deva se desenvolver uma definição concreta de um domínio organizacional: um produto ou serviço específico e segmento de mercado alvo;

ii) O problema de engenharia, que aborda a criação de um sistema que coloca em operação de gestão de solução real para o problema empresarial. A criação de um sistema desse tipo exige uma gestão para selecionar uma tecnologia adequada;

iii) O problema administrativo, que é descrito nas teorias de gestão, estando principalmente na tentativa de reduzir a incerteza dentro do sistema de organização, ou em termos do modelo atual, de racionalizar e estabilizar as atividades com sucesso resolvendo os problemas enfrentados pela organização durante a redução da incerteza. Na figura 1 é representado o ciclo adaptativo.

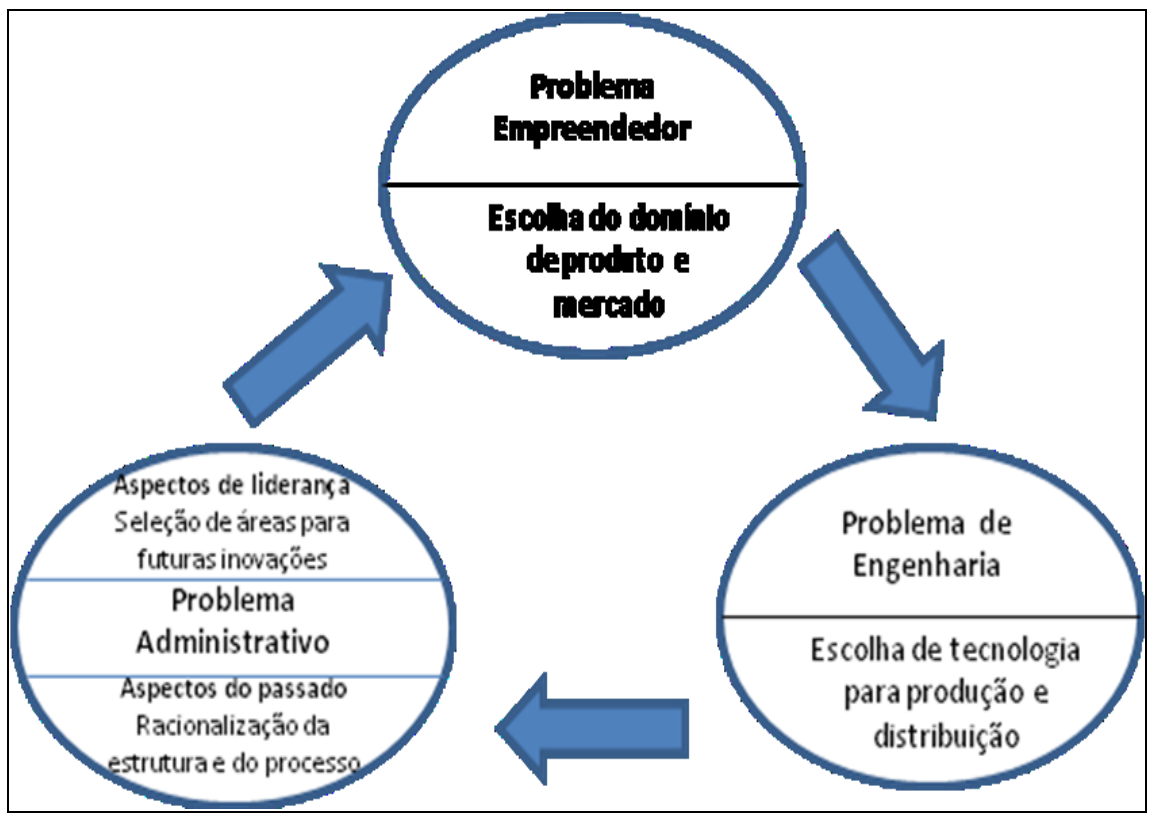

Figura 1 Ciclo adaptativo de Miles e Snow Fonte: Miles e Snow (1978, p. 24)

Gimenez (1997) e Castro Jr. et al. (2014) creditam as personalidades dos principais gestores em qualquer organização à função importante de explorar as escolhas estratégicas por meio da avaliação do papel exercido pelas características pessoais de tomadores de 
decisão em empresas. Apresenta-se a seguir um quadro com o resumo da tipologia de Miles e Snow (1978). Vide no quadro 1 com as categorias estratégicas e a descrição de cada uma delas.

\begin{tabular}{|c|c|}
\hline $\begin{array}{c}\text { Categoria } \\
\text { Estratégica }\end{array}$ & DESCRIÇÃO \\
\hline $\begin{array}{l}\text { Estratégia } \\
\text { Defensiva }\end{array}$ & $\begin{array}{l}\text { Uma empresa seguindo esta estratégia procura localizar e manter uma linha de } \\
\text { produtos/serviços relativamente estável. Seu foco concentra-se em uma gama de } \\
\text { produtos/serviços mais limitada do que seus concorrentes e tenta proteger seu } \\
\text { domínio através da oferta de produtos com melhor qualidade, serviços superiores, } \\
\text { e/ou menores preços. Não procura estar entre os líderes da indústria, restringindo-se } \\
\text { àquilo que sabe fazer tão bem ou melhor que qualquer um. }\end{array}$ \\
\hline $\begin{array}{c}\text { Estratégia } \\
\text { Prospectora }\end{array}$ & $\begin{array}{l}\text { Uma empresa que adota esta estratégia está continuamente ampliando sua linha de } \\
\text { produtos/serviços. Enfatiza a importância de oferecer novos produtos/serviços em } \\
\text { uma área de mercado relativamente mais ampla. Valoriza ser uma das primeiras a } \\
\text { oferecer novos produtos, mesmo que todos os esforços não se mostrem altamente } \\
\text { lucrativos. }\end{array}$ \\
\hline $\begin{array}{c}\text { Estratégia } \\
\text { Analítica }\end{array}$ & $\begin{array}{l}\text { Uma empresa que segue esta estratégia tenta manter uma linha limitada de } \\
\text { produtos/serviços relativamente estável e ao mesmo tempo tenta adicionar um ou } \\
\text { mais novos produtos/serviços que foram bem sucedidos em outras empresas do setor. } \\
\text { Em muitos aspectos é uma posição intermediária entre as estratégias defensiva e } \\
\text { prospectora. }\end{array}$ \\
\hline $\begin{array}{c}\text { Estratégia } \\
\text { Reativa }\end{array}$ & $\begin{array}{l}\text { A firma que adota uma estratégia reativa exibe um comportamento mais inconsistente } \\
\text { do que os outros tipos. É uma espécie de não-estratégia. Não arrisca em novos } \\
\text { produtos/serviços a não ser quando ameaçada por competidores. A abordagem típica } \\
\text { é "esperar para ver" e responder somente quando forçada por pressões competitivas } \\
\text { para evitar a perda de clientes importantes e/ou manter lucratividade. }\end{array}$ \\
\hline
\end{tabular}

Quadro 1 Categorias Estratégicas de Miles e Snow

Fonte: Gimenez et al. (1999)

Gimenez (1998) estudou e descreveu como a cognição, adotada por dirigentes, está relacionada à forma como adquirem, armazenam e usam conhecimento em pequenas empresas na gestão estratégica. Existe o interesse por diferenças no processamento de informações (estilo cognitivo) em oposição a estudos de habilidade cognitiva (nível cognitivo). Enquanto diferentes níveis de habilidades cognitivas podem levar a diferentes níveis de desempenho, estilos não têm relação com eficácia ou eficiência e podem ser julgados mais ou menos adequados a determinadas situações.

Segundo Gimenez et al. (1999), uma taxonomia de estratégias genéricas que tem chamado a atenção de pesquisadores em administração estratégica é a fornecida por Miles e Snow (1978). Ao contrário da classificação de Porter (1980), essa é mais abrangente e oferece melhores qualidades conceituais para um agrupamento de empresas mais preciso. A força dessa taxonomia é que ela especifica relacionamentos entre estratégia, estrutura e processos 
de uma forma que permite a identificação das organizações como universos integrados em interação com seus ambientes.

Slater e Olson (2000) assumem a premissa básica da literatura, uma vez que a implementação de estratégias diferentes se dá pelas distintas configurações de práticas organizacionais para obter o desempenho ideal.

Para a correlação entre estilo cognitivo e a estratégia foi utilizada a visão de estratégia presente na obra de Miles e Snow (1978), a taxonomia foi escolhida, pois tendo sido estudada e validada através de pesquisas (HAMBRICK, 1983; CONANT, MOKWA E VANADARAJAN, 1990) e é baseada na suposição de que a organização constrói o ambiente com o qual vai lidar, ou, em outras palavras, a organização somente vê no ambiente os aspectos com os quais quer lidar.

Conant, Mokwa e Varadarajan (1990) desenvolveram uma nova escala multi-item para operacionalizar a tipologia estratégica desenvolvida por Miles e Snow (1978). A escala multiitem foi empregada para analisar a relação entre os tipos estratégicos, competências de marketing e desempenho organizacional. Os resultados dessa a análise sugerem que, nas competências de marketing das organizações, o comportamento prospector é superior aos demais tipos de comportamento estratégico, analista, defensivo, e organizações de reativas. Todos os três arquétipos se apresentaram de maneira estável por executar igualmente, em termos de reativos de rentabilidade e superar. A recém-desenvolvida escala dos tipos de comportamento estratégico funciona bem e parece possuir potencial de gestão e de pesquisa significativo. A escala se apoia teoricamente, e é considerada de fácil aplicação, além de possui valor diagnóstico para todos os tipos de estratégias e tipos de organizações. No quadro 2, são apresentados o ciclo adaptativo, as dimensões do ciclo e a característica estratégica.

\begin{tabular}{|c|c|c|c|c|c|c|}
\hline \multirow{2}{*}{$\begin{array}{l}\text { Componentes do } \\
\text { ciclo adaptativo: }\end{array}$} & \multirow{2}{*}{ Dimensões } & \multicolumn{5}{|c|}{ Comportamentos Estratégico } \\
\hline & & Defensor & Prospector & Analista & \multicolumn{2}{|l|}{ Reativo } \\
\hline \multirow{3}{*}{$\begin{array}{c}\text { Problema } \\
\text { Empreendedor } \\
\text { e Soluções }\end{array}$} & $\begin{array}{lr}\text { Domínio } & \text { de } \\
\text { produtos } & \mathrm{e} \\
\text { mercados } & \\
\end{array}$ & $\begin{array}{l}\text { Estreito e } \\
\text { cuidadosamente } \\
\text { focado }\end{array}$ & $\begin{array}{l}\text { Amplo e em } \\
\text { expansão } \\
\text { contínua }\end{array}$ & $\begin{array}{l}\text { Segmentado e } \\
\text { cuidados com } \\
\text { ajustes }\end{array}$ & $\begin{array}{l}\text { Irregular } \\
\text { transitório }\end{array}$ & $\mathrm{e}$ \\
\hline & $\begin{array}{l}\text { Postura de } \\
\text { sucesso }\end{array}$ & $\begin{array}{l}\text { Proeminente em } \\
\text { seu Mercado }\end{array}$ & $\begin{array}{l}\text { Ativa iniciação } \\
\text { de mudança }\end{array}$ & $\begin{array}{l}\text { Seguidores } \\
\text { cuidadosos de } \\
\text { mudança }\end{array}$ & $\begin{array}{l}\text { Investidas } \\
\text { oportunistas } \\
\text { postura } \\
\text { adaptação }\end{array}$ & \\
\hline & $\begin{array}{l}\text { Monitorame } \\
\text { nto } \\
\text { ambiental }\end{array}$ & $\begin{array}{lr}\text { Baseado no } \\
\text { domínio } \\
\text { cuidadoso/ } \\
\text { forte } \\
\text { monitoramento } \\
\text { organizacional }\end{array}$ & $\begin{array}{l}\text { Orientado para } \\
\text { o mercado e } \\
\text { ambiente } \\
\text { busca agressiva }\end{array}$ & $\begin{array}{l}\text { Orientado para } \\
\text { a concorrência } \\
\text { e completo }\end{array}$ & $\begin{array}{l}\text { Esporádico } \\
\text { dominado } \\
\text { tópicos } \\
\text { específicos }\end{array}$ & $\begin{array}{l}\text { e } \\
\text { por }\end{array}$ \\
\hline
\end{tabular}




\begin{tabular}{|c|c|c|c|c|c|}
\hline \multirow{3}{*}{$\begin{array}{l}\text { Componentes do } \\
\text { ciclo adaptativo: }\end{array}$} & \multirow{2}{*}{ Dimensões } & \multicolumn{4}{|c|}{ Comportamentos Estratégico } \\
\hline & & Defensor & Prospector & Analista & Reativo \\
\hline & Crescimento & $\begin{array}{lr}\text { Penetração } & \\
\text { cuidadosa } & \text { e } \\
\text { avanços } & \text { de } \\
\text { produtividade } & \end{array}$ & $\begin{array}{l}\text { Desenvolviment } \\
\text { o de produtos e } \\
\text { mercados e } \\
\text { diversificação }\end{array}$ & $\begin{array}{l}\text { Penetração } \\
\text { assertiva e } \\
\text { cuidadoso } \\
\text { desenvolvime } \\
\text { nto } \\
\text { produtos de } \\
\text { mercados } \\
\end{array}$ & $\begin{array}{l}\text { Mudanças } \\
\text { apressadas }\end{array}$ \\
\hline \multirow{3}{*}{$\begin{array}{l}\text { Problema de } \\
\text { Engenharia e } \\
\text { Soluções }\end{array}$} & $\begin{array}{l}\text { Objetivo } \\
\text { tecnológico }\end{array}$ & $\begin{array}{l}\text { Eficiência de } \\
\text { custos }\end{array}$ & $\begin{array}{l}\text { Flexibilidade e } \\
\text { inovação }\end{array}$ & $\begin{array}{l}\text { Sinergia } \\
\text { tecnológica }\end{array}$ & $\begin{array}{l}\text { Desenvolvimento } \\
\text { e conclusão de } \\
\text { projetos }\end{array}$ \\
\hline & $\begin{array}{l}\text { Amplitude } \\
\text { tecnológica }\end{array}$ & $\begin{array}{l}\text { Tecnologia } \\
\text { única, focal/ } \\
\text { expertise básica }\end{array}$ & $\begin{array}{l}\text { Tecnologias } \\
\text { múltiplas/ } \\
\text { avançando na } \\
\text { fronteira }\end{array}$ & $\begin{array}{l}\text { Tecnologias } \\
\text { interrelacionad } \\
\text { as na fronteira }\end{array}$ & $\begin{array}{l}\text { Aplicações } \\
\text { tecnológicas } \\
\text { mutáveis/ } \\
\text { Fluidez }\end{array}$ \\
\hline & $\begin{array}{l}\text { Anteparos } \\
\text { tecnológicos } \\
\text { (buffers) }\end{array}$ & $\begin{array}{lr}\text { Programas } & \text { de } \\
\text { manutenção } & \mathrm{e} \\
\text { padronização } & \end{array}$ & $\begin{array}{l}\text { Habilidades de } \\
\text { pessoal técnico/ } \\
\text { diversidade }\end{array}$ & $\begin{array}{l}\text { Incrementalis } \\
\text { mo e sinergia }\end{array}$ & $\begin{array}{lr}\text { Habilidade } & \text { de } \\
\text { experimentar } & \mathrm{e} \\
\text { improvisar } & \\
\text { soluções } & \\
\end{array}$ \\
\hline \multirow{4}{*}{$\begin{array}{c}\text { Problema } \\
\text { Administrativo } \\
\text { e } \\
\text { Soluções }\end{array}$} & $\begin{array}{l}\text { Coalizão } \\
\text { dominante }\end{array}$ & $\begin{array}{l}\text { Finanças } \\
\text { Produção }\end{array}$ & $\begin{array}{l}\text { Marketing } \\
\text { P\&D }\end{array}$ & $\begin{array}{l}\text { Pessoal de } \\
\text { Planejamento }\end{array}$ & $\begin{array}{l}\text { Solucionadores } \\
\text { de problemas }\end{array}$ \\
\hline & $\begin{array}{l}\text { Planejament } \\
\text { o }\end{array}$ & $\begin{array}{l}\text { De dentro para } \\
\text { fora/ dominado } \\
\text { por controle }\end{array}$ & $\begin{array}{lr}\text { Busca } & \mathrm{de} \\
\text { problemas } & \mathrm{e} \\
\text { oportunidades// } & \\
\text { perspectiva } & \mathrm{de} \\
\text { programas } & \text { ou } \\
\text { campanhas } & \\
\end{array}$ & $\begin{array}{l}\text { Abrangente } \\
\text { com mudanças } \\
\text { incrementais }\end{array}$ & $\begin{array}{lr}\text { Orientado } & \text { por } \\
\text { crises } & \mathrm{e} \\
\text { desarticulado } & \end{array}$ \\
\hline & Estrutura & $\begin{array}{l}\text { Funcional/ } \\
\text { Autoridade de } \\
\text { linha }\end{array}$ & $\begin{array}{l}\text { Por produtos } \\
\text { e/ou mercados }\end{array}$ & $\begin{array}{l}\text { Dominada por } \\
\text { assessores/ } \\
\text { orientada por } \\
\text { matriz }\end{array}$ & $\begin{array}{l}\text { Autoridade } \\
\text { formal rígida/ } \\
\text { desenho } \\
\text { operacional solto }\end{array}$ \\
\hline & Controle & $\begin{array}{l}\text { Centralizado, } \\
\text { formal e ancorado } \\
\text { em aspectos } \\
\text { financeiros }\end{array}$ & $\begin{array}{l}\text { Desempenho no } \\
\text { mercado/ } \\
\text { volume de } \\
\text { vendas }\end{array}$ & $\begin{array}{l}\text { Métodos } \\
\text { múltiplos/cálc } \\
\text { ulos de riscos } \\
\text { cuidados/contr } \\
\text { ibuição de } \\
\text { vendas }\end{array}$ & $\begin{array}{l}\text { Evitar } \\
\text { problemas/ } \\
\text { resolver } \\
\text { problemas } \\
\text { remanescentes }\end{array}$ \\
\hline
\end{tabular}

Quadro 2 Dimensões do Ciclo Adaptativo e Características dos Tipos Estratégicos Fonte: Conant, Mokwa e Varadarajan (1990, p.367) e Gimenez et al. (1999, p.61)

A tipologia de Miles e Snow (1978) foi utilizada em pesquisa sobre as IES no sul do Brasil por Moreira et al. (2009), e verificada a relação entre perfil estratégico e performance, assim como a identificação do perfil de comportamento estratégico adotado com maior frequência pelas IES privadas, foi o comportamento Defensivo.

\section{METODOLOGIA}

Esta pesquisa pode ser caracterizada como quantitativa e do tipo survey e que tem como característica principal o interesse de produzir descrições quantitativas de uma 
população e faz uso de um instrumento pré-definido, geralmente um questionário (FREITAS et al., 2000).

Os dados foram coletados valendo-se da ferramenta Lime Survey, no qual um link foi criado para todos os coordenadores de curso de uma universidade pública federal. Esta instituição possui mais de 100 cursos de graduação autorizados e em funcionamento. Foi enviado email para todos os coordenadores de curso informando o objetivo da pesquisa com o link para preenchimento do questionário. Do total de coordenadores, 46 de diferentes áreas, responderam o questionário, representando a amostra por conveniência, conforme ensina Hair Jr. et. al. (2009), que foi analisada.

Para a identificação das variáveis que apoiaram a mensuração do construto comportamento estratégico, levou-se em consideração o estudo de Conant, Mokwa e Varadarajan (1990), com ajustes de nomenclaturas ao segmento estudado. Essa escala é consistente, de fácil administração e possui valor no diagnóstico para os estrategistas e suas organizações (CONANT; MOKWA; VARADARAJAN, 1990).

Além disso, destaca-se que o instrumento já foi replicado por outros estudos e demonstrou consistência nos resultados, a exemplo de Gimenez et al. (1999); Gulini (2005); Teixeira, Rossetto e Carvalho (2009); Gardelin, Rossetto e Verdinelli (2011); Ribeiro, Rossetto e Verdinelli (2011) e Silveira-Martins et al. (2014).

Registra-se que após as adequações semânticas, foi realizado validação de face e préteste do instrumento junto a três docentes que já foram coordenadores de curso em instituições públicas de diferentes regiões do país por sistema de videoconferência, sendo discutido e corroborado por todos.

Para análise dos dados coletados, foram utilizados softwares e técnicas estatísticas específicas para cada construto e/ou suas relações. Os dados foram tabulados no software Excel ${ }^{\circledR}$, versão 2007; na sequência, foram aplicados métodos multidimensionais para o tratamento dos dados, conforme metodologia de Verdinelli e Escobar (2011). Valendo-se do software Statistica 8.0, os dados foram organizados em uma matriz disjuntiva completa onde cada um dos 11 aspectos utilizados no questionário foram representados por colunas e as respostas por linhas, que serão preenchidas com os valores: 0 (zero) quando não assinalado pelo respondente e 1 (um) quando assinalado.

De posse desta matriz, foi realizada a análise de correspondência simples que consiste em uma técnica de análise exploratória de dados adequada para analisar tabelas de duas 
entradas ou tabelas de múltiplas entradas, levando em conta algumas medidas de correspondência entre linhas e colunas, identificando as empresas e os comportamentos com maior associação. Em seguida, realizou-se a análise de conglomerados usando o método ward e a distância euclidiana como medida de parecença.

\section{ANÁLISE DOS DADOS}

Os coordenadores mais correlatos foram identificados, de acordo com cada tipo de comportamento, após a inserção de uma variável suplementar - tipo puro - relacionada a cada uma das tipologias. No Gráfico 1 pode-se observar que o coordenador identificado pelo número 32 é o que possui maior conexão com o comportamento estratégico reativo. A inércia acumulada foi de $21,28 \%$ para todas as análises.

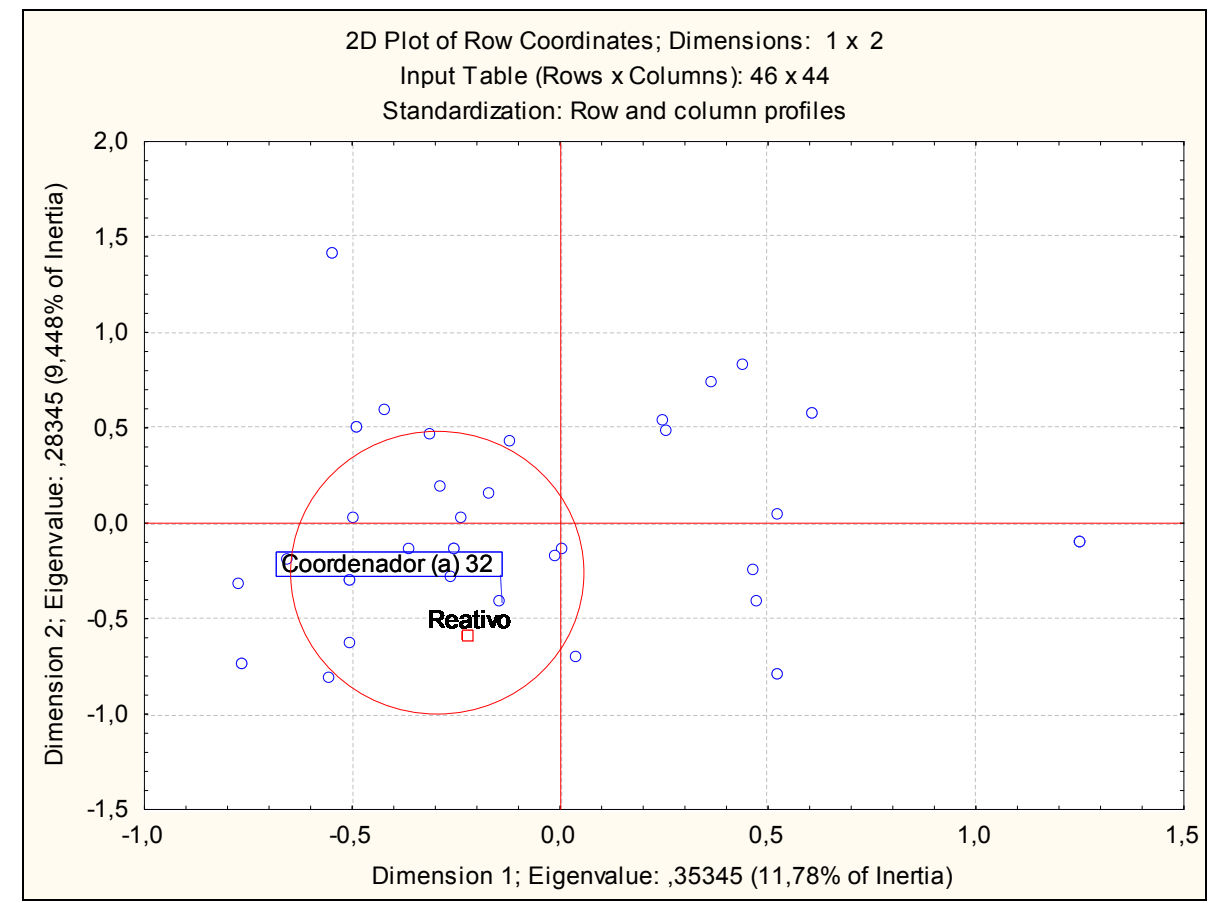

Gráfico 1 Comportamento reativo Fonte: Dados da pesquisa

Em relação ao comportamento defensor, pode-se obsevar no Gráfico 2, que esta orientação está associada ao coordenador identificado com o número 27. 


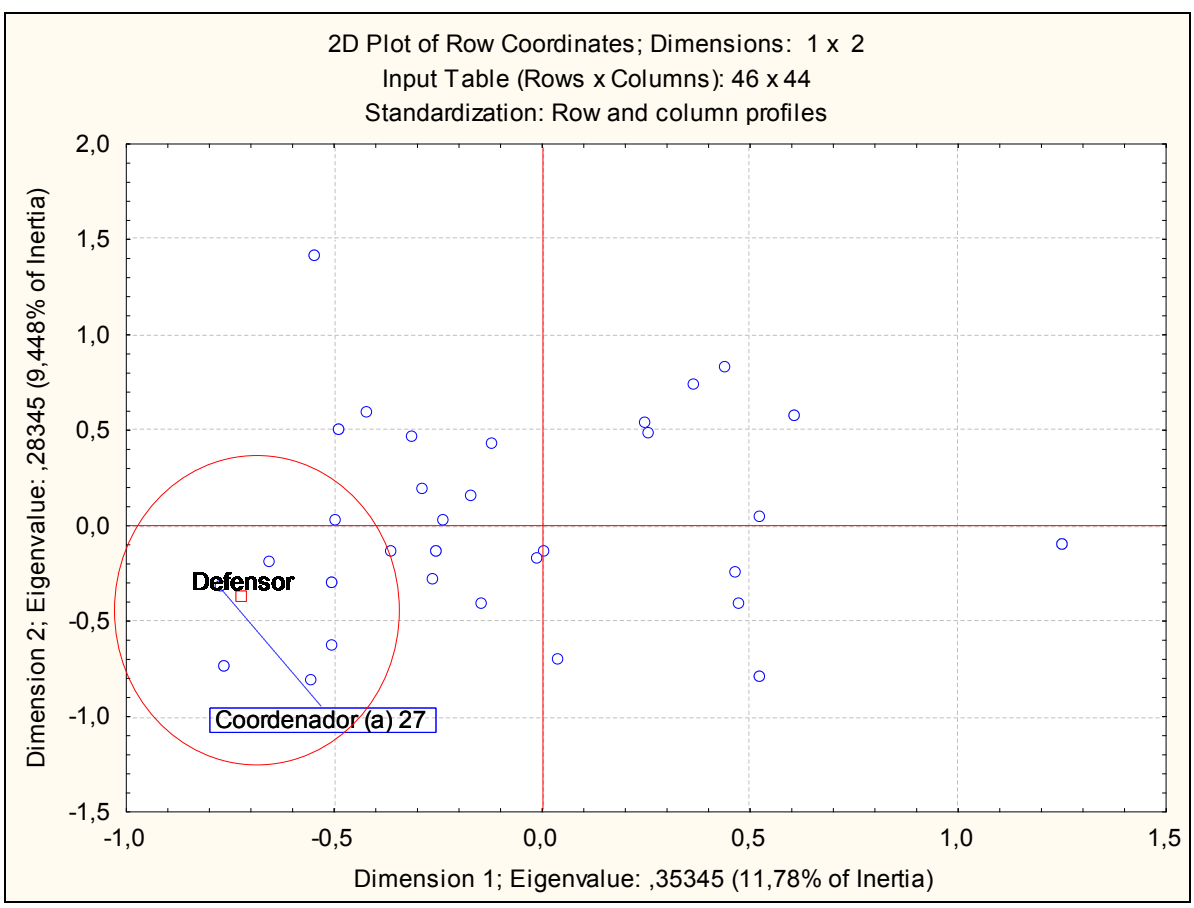

Gráfico 2 Comportamento defensor Fonte: Dados da pesquisa

Da mesma forma, no Gráfico 3 identificou-se que o comportamento analista possui o coordenador nominado com o número 17 como sendo a referência para caracterização do agrupamento hierárquico a que pertence.

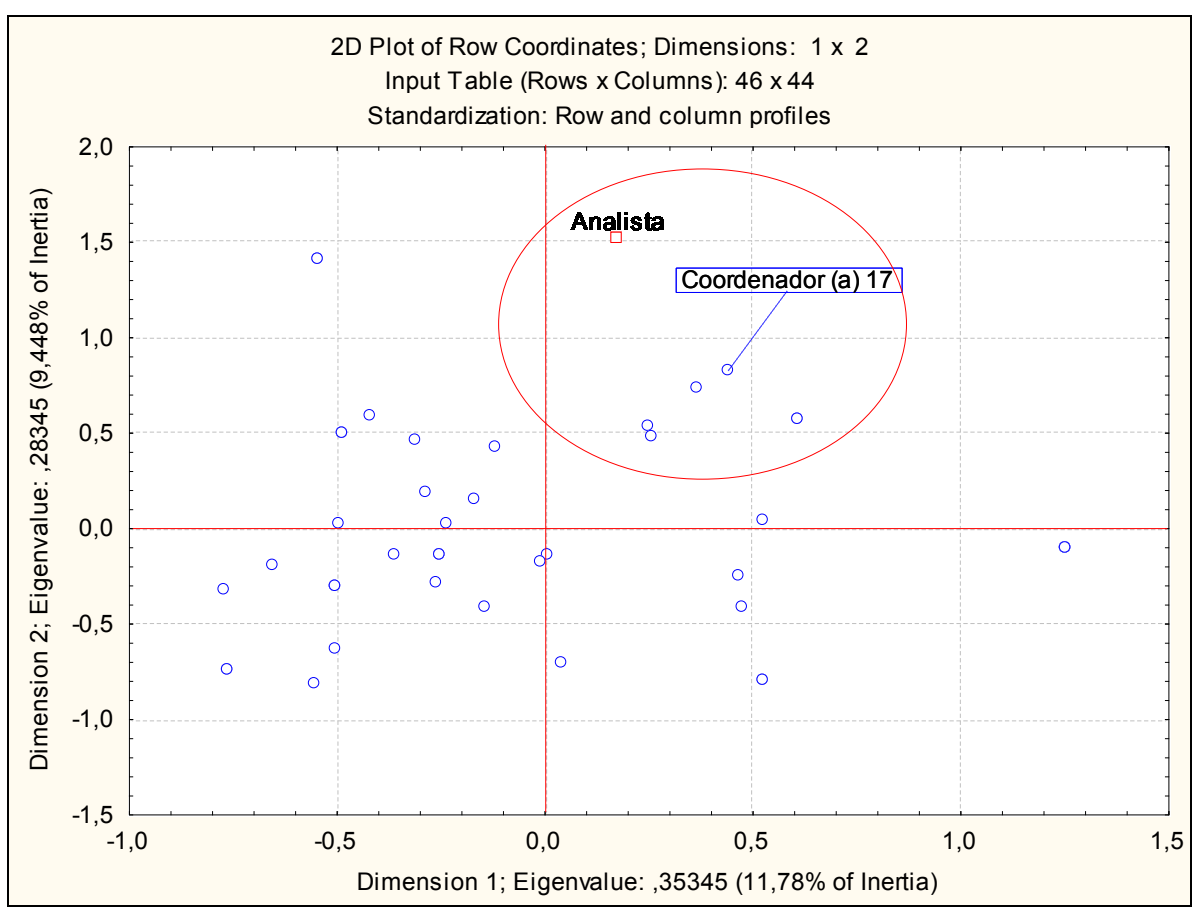

Gráfico 3 Comportamento analista

Fonte: Dados da pesquisa 
O coordenador $\mathrm{n}^{\mathrm{o}} 2$ foi identificado com maior proximidade ao comportamento estratégico prospector. Tal observação pode ser melhor visualizada na representação do Gráfico 4.

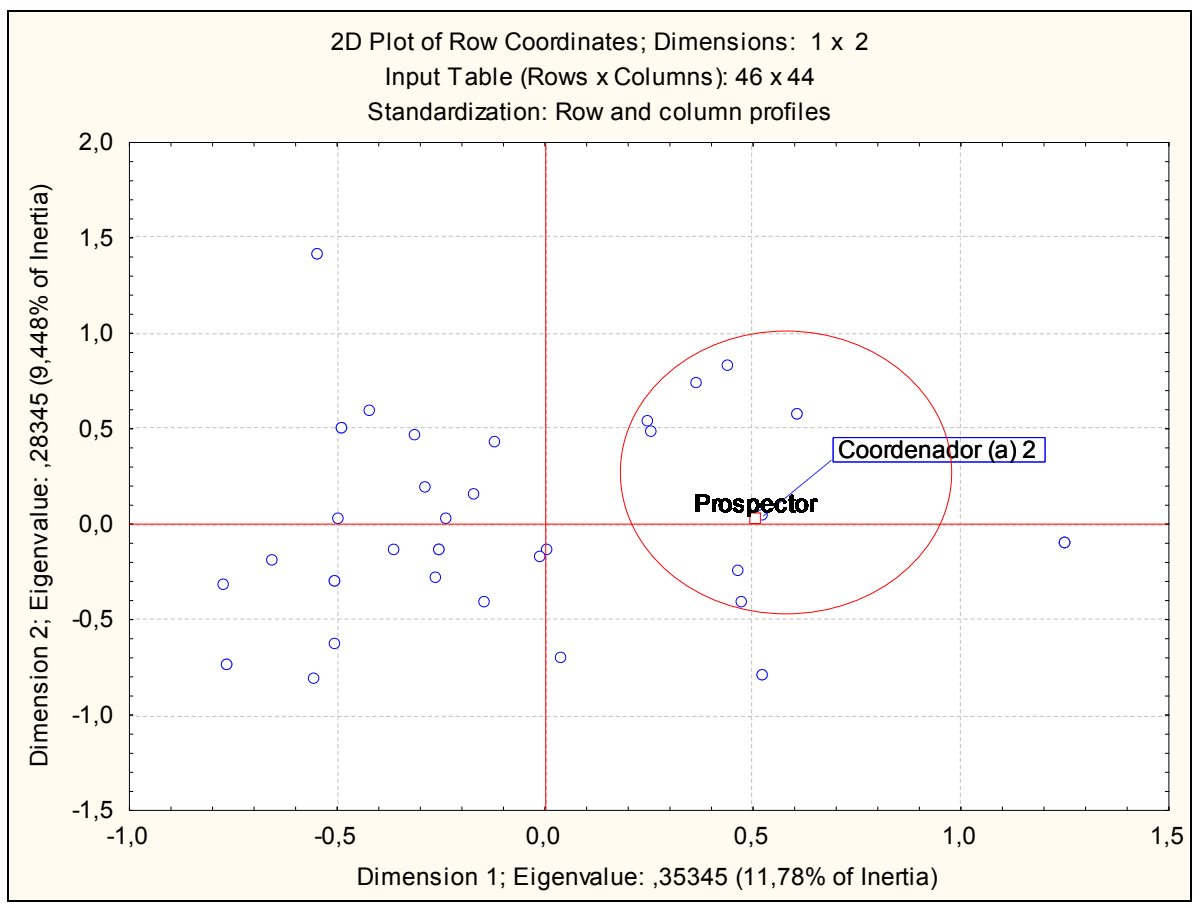

Gráfico 4 Comportamento prospector Fonte: Dados da pesquisa

$\mathrm{Na}$ sequência foi realizada pelo processo de análise de conglomerados, usando a medida de parecença a distância euclidiana e como mecanismo de junção entre os coordenadores o método de Ward. A identificação dos conglomerados referentes a cada tipologia estratégica levou em consideração as empresas apontadas nos Gráficos 1, 2, 3 e 4. De acordo com Verdinelli e Escobar (2011) a utilização de todos estes procedimentos garante que os grupos obtidos no primeiro momento podem ser identificados com precisão. $\mathrm{O}$ agrupamento completo, com a identificação das tipologias de cada conglomerado pode ser observado no Gráfico 5. 


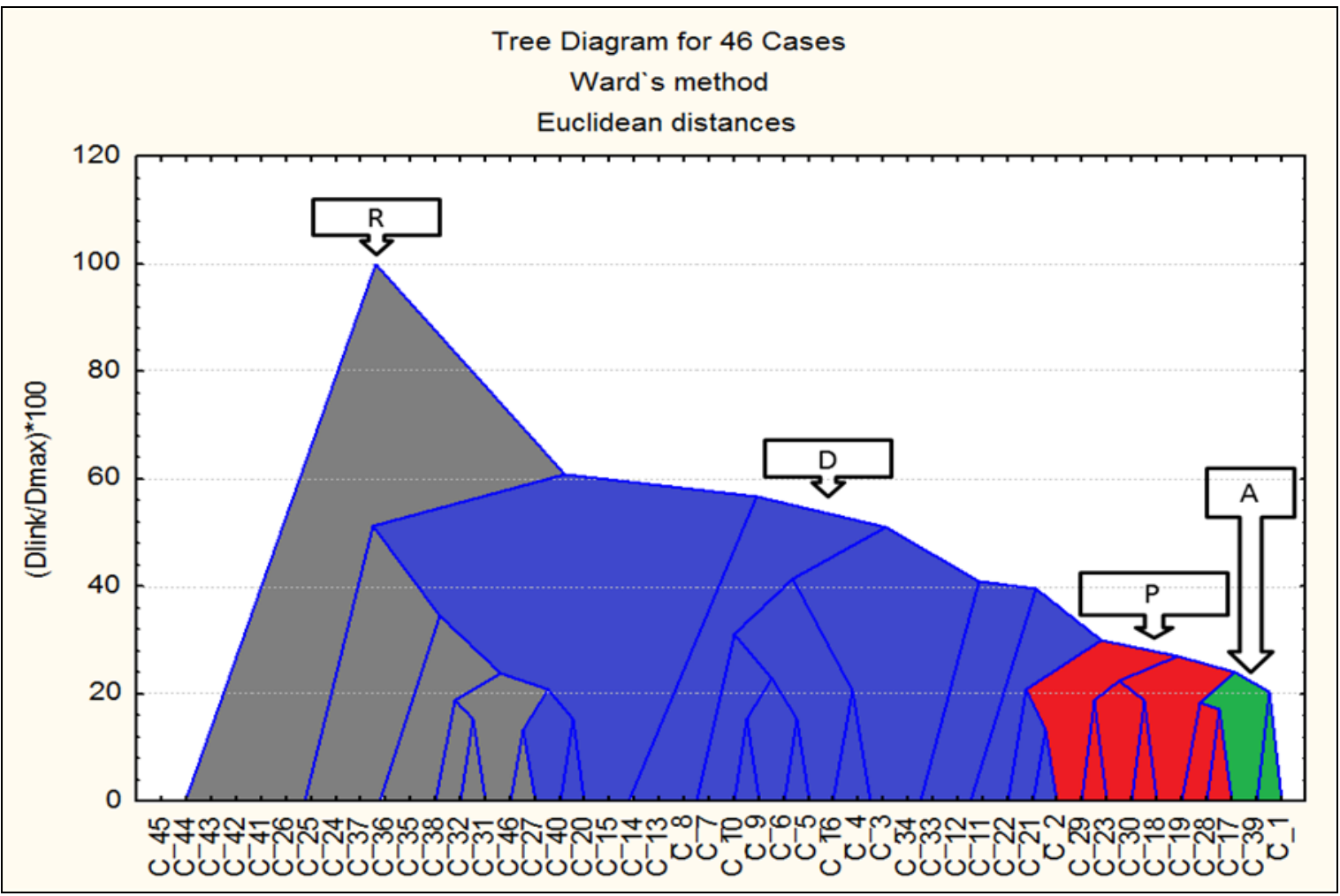

Gráfico 5 Conglomerados vs. comportamentos Fonte: Dados da pesquisa

Através do Gráfico 5, já é possível perceber que o número de gestores com o comportamento estratégico defensor é superior aos demais. Para sanar quaisquer dúvidas, no Quadro 3 visualiza-se o total de coordenadores por comportamento estratégico em ordem decrescente de quantidade das orientações adotadas.

\begin{tabular}{|c|l|c|}
\hline RANKING & \multicolumn{1}{|c|}{ TIPOLOGIA } & QUANTIDADE DE COORDENADORES \\
\hline $1^{\mathbf{o}}$ & Defensor & 21 \\
\hline $2^{\mathbf{o}}$ & Reativo & 16 \\
\hline $3^{\mathbf{o}}$ & Prospector & 7 \\
\hline $4^{\mathbf{o}}$ & Analista & 2 \\
\hline \multicolumn{2}{|c|}{ TOTAL } & $\mathbf{4 6}$ \\
\hline
\end{tabular}

Quadro 3 Agrupamento hierárquico vs. Tipologias Fonte: Dados da pesquisa

Desta forma, os dados analisados indicam que o comportamento estratégico predominante, nos coordenadores da Universidade Pública Federal analisada, é o defensor.

Destacam-se as principais características do perfil predominante dos coordenadores, encontrado pelo estudo. Pela teoria de Miles e Snow (1978), Conant, Mokwa e Varadarajan (1990) caracterizam os profissionais com a postura Defensor: 
- No que tange o Problema Empreendedor e Soluções: Domínio de produtos e mercados são estreitos e cuidadosamente focados; Postura de sucesso, são proeminente em seu mercado; Monitoramento ambiental, são baseados no domínio e cuidadosos, sendo fortes no monitoramento organizacional; quanto ao Crescimento, apresentam uma penetração cuidadosa e buscando avanços de produtividade.

- Em relação ao Problema de Engenharia e Soluções, possui as seguintes características: Objetivo tecnológico, buscam a eficiência por meio dos custos; Amplitude tecnológica, são adeptos de tecnologia única e focal (expertise básica); Anteparos tecnológicos, utilizam-se de programas de manutenção e padronização.

- Para o Problema Administrativo e Soluções, caracterizam-se: Coalizão dominante privilegiam as áreas de produção e finanças; quanto ao Planejamento, partem de dentro para fora (dominado por controle); sua Estrutura é funcional (autoridade de linha); quanto ao Controle, são centralizados, formais e ancorado em aspectos financeiros.

Gimenez et al. (1999) afirmam que seguindo a estratégia defensora, a organização procura localizar e manter uma linha de produtos/serviços, relativamente estável. Ela busca concentra-se em limitar seu foco em uma gama de produtos/serviços, diferentemente de seus concorrentes. Tenta proteger seu domínio por meio da oferta de produtos com melhor qualidade, serviços superiores, e/ou menores preços. Não procura estar entre os líderes, restringindo-se àquilo que sabe fazer tão bem ou melhor que qualquer um.

\section{CONSIDERAÇÕES FINAIS}

A presente pesquisa objetivou identificar o comportamento estratégico predominante dos coordenadores de uma Universidade Pública Federal, conforme tipologia desenvolvida por Miles e Snow (1978). Os resultados apontaram que a orientação proeminente no corpo de coordenadores da Universidade é o defensor, seguido do reativo, prospector e analista, nesta ordem.

Esta constatação reflete que a maioria dos coordenadores orienta-se para uma relação direcionada a manutenção das práticas originais do seu curso, com tímida atuação na prospecção de serviços inovadores. De toda a forma, este perfil de orientação estratégica busca destacar-se no que fora proposto nos projetos pedagógicos, sem prospectar novidades, mas com uma postura de efetivação das práticas projetadas. 
Além destes resultados, o que chama a atenção é o segundo comportamento identificado junto aos coordenadores de curso - o reativo. A diferença entre o defensor e o reativo é de apenas 5 respondentes, e entre este e o terceiro comportamento com maior número de adeptos é de 9 coordenadores. Logo, pode-se perceber que o comportamento reativo, embora não seja o que possui maior número de respondentes, apresenta-se com destaque.

Desta maneira, estes resultados sugerem que os coordenadores de muitos cursos realizam de maneira muito singela o acompanhamento sobre as necessidades do ambiente, neste caso em específico as demandas da sociedade. Este posicionamento pode desdobrar em uma formação com gaps de conhecimento ou defasagem sobre as necessidades do mercado. Por outro ângulo, os coordenadores reativos quando realizam as mudanças, estas tem a ser apressadas, e com um estratégia mal elaborada ou falha.

Destaca-se que os apontamentos realizados no decorrer desta pesquisa devem ser analisados sob a ótica deste objeto em específico, visto que a principal limitação desta pesquisa reside na amostra pesquisada, e suas particularidades. Desta maneira a presente pesquisa não possui o poder de generalização dos resultados.

Como sugestão para trabalhos futuros, instiga-se novas pesquisas que considerem a orientação estratégica dos coordenadores das demais universidades públicas federais, estaduais e municipais no País, analisando suas interfaces. Outra sugestão direciona-se a realização de estudos correlacionando o comportamento dos coordenadores (de diferentes IES) com o desempenho percebido do curso percebido. Neste sentido, acredita-se ser de grande valia a identificação da percepção dos acadêmicos sobre a gestão do curso, buscando verificar se existem congruências entre o relatado pelos coordenadores em relação ao percebido pelos alunos.

\section{REFERÊNCIAS}

AKKARI, A. J. Desigualdades educativas estruturais no Brasil: entre estado, privatização e descentralização. Educação \& Sociedade, v. 74, p. 163-189, 2001. Disponível em: $<$ http://www.scielo.br/pdf/\%0D/es/v22n74/a10v2274.pdf >. Acesso em: 24 mar. 2015.

BEAL, R. M.; YASAI-ARDEKANI, M. Perfomance implications of aligning CEO functional experiences with competitive strategies. Journal of Management, v. 26, n. 4, p. 733-762, 2000. 
BRUNALDI, K. R.; JUNGLES, A. E.; GIMENEZ, F. A. P. Comportamento estratégico e estilo cognitivo de dirigentes de pequenas empresas construtoras. In: ENCONTRO DE ESTUDOS EM ESTRATÉGIA, 3, 2007, São Paulo. Anais... São Paulo: 3Es, 2007.

CARNEIRO, J. M. T; CAVALCANTI, M. A. F; DESCHAMPS-SILVA, J. F. Porter revisitado: análise crítica da tipologia estratégica do mestre. Revista de Administração Contemporânea, v. 1, n. 3, p. 1-15. 1997.

CARVALHO, C. E. Relacionamento entre ambiente organizacional, capacidades, orientação estratégica e desempenho: um estudo no setor hoteleiro. 2011. 210f. Tese (Doutorado em Administração). Programa de Pós-Graduação em Administração, Universidade do Vale do Itajaí, Biguaçu, 2011.

CASTRO JUNIOR, D. F. L; SILVEIRA-MARTINS, E; MIURA, M. N; SCHIAVONI, M. A; DELUCA, M. A. M. Consignação de estratégias a partir da análise ambiental: um estudo de caso do grupo Jan Bebidas. Navus - Revista de Gestão e Tecnologia, v. 4, n. 2, 2014.

CENTRAL INTELLIGENCE AGENCY. The world factbook. Washington: CIA, 2015. Disponível em: <https://www.cia.gov/library/publications/the-worldfactbook/rankorder/rankorderguide.html> Acesso em: 27 mar. 2015.

COLLIER, D. A. The customer service and quality challenge. The Service Industries Journal. v. 7, n. 1, p. 77-90, 1987.

CONANT, J. S.; MOKWA, M. P.; VARADARAJAN, P. R. Strategic types, distinctive marketing competencies and organizational performance: a multiple measures-based study. Strategic Management Journal, v. 11, p. 365-383, 1990.

COVIN, J. G. Entrepeneurial versus conservative firms: a comparasion of strategies and performance. Journal of Management Studies, v. 25, n. 5, p. 339-462, 1991.

DESS, G. G.; DAVIS, P. S. Porter's (1980) generic strategies as determinants of strategic group membership and organizational performance. Academy of Management Journal, v. 27, n. 3, p. 467-488, 1984.

FERREIRA, J. M.; RAMOS, S. C. Escolha estratégica e estilos cognitivos: uma relação da tipologia de Miles e Snow e o modelo de Kirton. In: ENCONTRO NACIONAL DE ENGENHARIA DE PRODUÇÃO, 24., 2004, Florianópolis. Anais... Florianópolis: ENEGEP, 2004.

FREITAS, H.; OLIVEIRA, M.; SACCOL, A. Z.; MOSCAROLA, J. O método de pesquisa survey. Revista de Administração, v. 35, n. 3, p. 105-112, jul./set., 2000.

GARDELIN, J. P.; ROSSETTO, C. R.; VERDINELLI, M. A. A percepção da incerteza ambiental e do comportamento estratégico no processo de formulação de estratégias em pequenas empresas. In: ENCONTRO DE ESTUDOS EM ESTRATÉGIA, 5., 2011, Porto Alegre. Anais... Rio de Janeiro: ANPAD, 2011. 
GIMENEZ, F. A. P. Análise de concorrência e estratégia: uma comparação entre empresas de alta tecnologia e de setores tradicionais. . In: ENCONTRO NACIONAL DE ENGENHARIA DE PRODUÇÃO, 17., 1997, Gramado. Anais... Gramado: ENEGEP, 1997.

. Escolhas estratégicas e estilo cognitivo: um estudo com pequenas empresas. Revista de Administração Contemporânea, v. 2, n. 1, p. 27-45, 1998.

.; PELISSON, C; KRÜGER, E; HAYASHI JUNIOR, P. Estratégia em pequenas empresas: uma aplicação do modelo de Miles e Snow. Revista de Administração Contemporânea, v. 3, n. 2, p. 53-74, 1999.

GULINI, P. L. Ambiente organizacional, comportamento estratégico e desempenho empresarial: um estudo no setor de provedores de internet de Santa Catarina. 2005. 160f. Dissertação (Mestrado Acadêmico em Administração) - Programa de Pós-Graduação em Administração, Universidade do Vale do Itajaí, Biguaçu, 2005.

Hair JR., J. F..; Anderson R. E.; Tatham, R. L; Black, W. C. Análise multivariada de dados. 6. ed. Porto Alegre: Bookman, 2009.

HAMBRICK, D. C. Operationalizing the concept of business-level strategy in research. Academy of Management Review. v. 5, n. 4, p. 567-576, 1980.

Strategic awareness within top management teams. Strategic Management Journal, v. 2, n. 3, p. 263-279, 1981.

Some tests of the effectiveness and functional attributes of Miles and Snow's strategic types. Academy of Management Journal, v. 26, n. 1, p. 5-26, 1983.

. On the staying power of defenders, analyzers, and prospectors. Academy of Management Executive, v. 17, n. 4, p. 115-118, 2003.

IBGE - INSTITUTO BRASILEIRO DE GEOGRAFIA E ESTATÍSTICA. Pesquisa anual de serviços - 2011. v. 13, Rio de Janeiro: IBGE, 2011. Disponível em:

$<$ http://www.ibge.gov.br/home/estatistica/economia/comercioeservico/pas/pas2011/> Acesso em: 27 mar. 2015.

INEP - INSTITUTO NACIONAL DE ESTUDOS E PESQUISAS EDUCACIONAIS ANÍSIO TEIXEIRA. Censo da educação superior 2012: resumo técnico. Brasília: INEP, 2014. Disponível em: $<$ http://portal.inep.gov.br/web/censo-da-educacao-superior/resumostecnicos>. Acesso em: 27 mar. 2015.

MATTAR, F. N. Pesquisa de marketing: metodologia e planejamento. 5. ed., São Paulo: Atlas, 1999.

MILES, R. E; SNOW, C. C. Organizational strategy, structure, and process. New York: McGraw-Hill, 1978. 
MINTZBERG, H. Strategy-making in three modes. California Management Review. v. 16, p. 44-53, dec., 1973.

Generic strategies: toward a comprehensive framework. Advances in Strategic Management. v. 5, p. 1-67, 1988.

MOREIRA, C. R; ARRUDA, G; DALMORO, M; PEREIRA, B. A. D. A relação entre estratégia e performance em instituições de ensino superior privadas da região Sul. FACEF Pesquisa, v. 12, p. 92-106, 2009.

ONUSIC, L. M. A qualidade de serviços de ensino superior o caso de uma Instituição de Ensino Público. In: ENCONTRO DA ANPAD - ENANPAD, 35, 2011. Anais... Rio de Janeiro: ANPAD. 2011.

PORTER, M. E. Competitive strategy. New York: Free Press, 1980.

RHYNE, D. M. The impact of demand management on service system performance. The Service Industries Journal. v. 8, n. 4, p. 446-458, 1988.

RIBEIRO, R.; ROSSETTO, C. R.; VERDINELLI, M. A. Comportamento estratégico de uma empresa e a visão baseada em recursos: um estudo no setor varejista de material de construção. Gestão e Produção, v. 18, n. 1, p. 175-192, 2011.

ROBINSON JR., B. R.; PEARCE II, J. A. Planned patterns of strategic behavior and their relationship to business-unit performance. Strategic Management Journal, v. 9, p. 43-60, 1988.

SEGEV, E. A systematic comparative analysis and synthesis of two business-level strategic typologies. Strategic Management Journal, v.10, p. 487-505, 1989.

SILVEIRA-MARTINS, E. Comportamento estratégico, ambidestria, incerteza ambiental e desempenho no processo de formulação de estratégias das empresas vinícolas brasileiras. 2012. 140f. Tese (Doutorado em Administração). Programa de Pós-Graduação em Administração, Universidade do Vale do Itajaí, Biguaçu, 2012.

.; ROSSETTO, C. R.; AÑAÑA, E. S. Ambidestria, exploração ou explotação e seus efeitos no desempenho organizacional de vinícolas brasileiras. Revista em Agronegócios e Meio Ambiente. v. 7, n. 3, p. 707-732, 2014.

SLATER, S. F.; OLSON, E. M. Strategy type and performance: the influence of sales force management. Strategic Management Journal, v. 21, p. 813-829, 2000.

.; _ _ _ HULT, T. M. The moderning influence of strategic orientation on the strategy formation capability - performance relationship. Strategic Management Journal, v. 27, 1221-1231, 2006.

SNOW, C. C; HREBINIAK L. G. Strategy, distinctive connpetence, and organizational performance. Administrative Science Quarterly. v. 25, n. 2, p. 317-336, 1980. 
TEIXEIRA, O. R. P.; ROSSETTO, C. R.; CARVALHO, C. E. A relação entre o ambiente organizacional e o comportamento estratégico no setor hoteleiro de Florianópolis - SC.

Revista Turismo Visão e Ação - Eletrônica, v. 11, n. 2, p. 157-174, 2009.

THOMAS, A. S.; LITSCHERT, R. J.; RAMASWAMY, K. The performance impact of strategy - manager coalignment: an empirical examination. Strategic Management Journal, v. 12, p. 509-522, 1991.

TURETA, C; ROSA, A. R; OLIVEIRA, V. C. S. Avaliação crítica de serviços educacionais: o emprego do modelo SERVQUAL. REGE - Revista de Gestão, v. 14, n. 4, p. 33-45, 2007.

VERDINELLI, M. A.; ESCOBAR, M. A. R. Tipos estratégicos genéricos de Miles e Snow imputados aos respondentes de uma escala multi-itens com uso de métodos multidimensionais. In: ENCONTRO DE ENSINO E PESQUISA EM ADMINISTRAÇÃO E CONTABILIDADE, 3., 2011, João Pessoa. Anais... João Pessoa: ENEPQ, 2011.

WHITE, R. E. Generic business strategies, organizational context and performance: an empirical investigation. Strategic Management Journal. v. 7, p. 217-231, 1986.

WILLBORN, W. Quality assurance audits and hotel management. The Service Industries Journal. v. 6, n. 3, p. 293-308, 1986.

ZAHRA, S. A.; PEARCE II, J. A. Research evidence on the Miles-Snow typology. Journal of Management, v.16, n. 4, p. 751-768, 1990.

ZAJAC, F. J; SHORTELL, S. M. Changing generic strategies: likelihood, direction, and performance implications. Strategic Management Journal v. 10, p. 413-430, 1989. 